\title{
Identification of insect community inhabiting Kaas plateau, Western ghats through cytochrome oxidase subunit I gene
}

\author{
Rakshit Ojha $^{1,2}$, S. K. Jalali ${ }^{*}$, T. M. Shivalingaswamy ${ }^{1}$, T. Venkatesan ${ }^{1}$, J. Poorani ${ }^{3}$ and $^{4}$ \\ S. M. Galande ${ }^{4}$ \\ ${ }^{1}$ Division of Molecular Entomology, ICAR-National Bureau of Agricultural Insect Resources, H. A. Farm Post, \\ Hebbal, Bengaluru- 560024 (Karnataka), INDIA \\ ${ }^{2}$ Department of Biotechnology, Center for Post Graduate Studies, Jain University, Jayanagar, Bengaluru- 560011 \\ (Karnataka), INDIA \\ ${ }^{3}$ National Research Centre for Banana, Thogamalai Road, Thayanur Post, Tiruchirapalli- 620102 (Tamil Nadu), INDIA \\ ${ }^{4}$ Department of Agricultural Entomology, College of Agriculture, Mahatma Phule Krishi Vidyapeeth, Shivaji \\ Nagar, Pune- 411005 (Maharashtra), INDIA \\ ${ }^{*}$ Corresponding author. E-mail: jalalisk1910@yahoo.co.in
}

Received: April 1, 2016; Revised received: August 26, 2016; Accepted: November 19, 2016

\begin{abstract}
Kaas Plateau is located in Western Ghats of Maharashtra, India. The region is one of its kinds being a biodiversity hot spot declared by UNESCO representing rich biodiversity of Western Ghats in India. However, insect biodiversity of this region has not been studied in detail so far. Thus, the present study was aimed at identification of insect community based on mitochondrial gene, cytochrome c oxidase subunit I (MT-CO1), for quick and reliable identification. During a collection trip, several insect specimens were collected, which belonged to seven insect orders, viz., Lepidoptera, Coleoptera, Hemiptera, Hymenoptera, Diptera, Orthoptera and Thysanoptera. Based on their morphological characteristics, specimens collected were delineated in to various orders and families. This resulted in determination of possible 15 different insect species, of which 7 could be identified up to species level. Remaining 8 sequences were matched with existing GenBank database that was $>96 \%$, therefore, were considered as putative species. One specimen could be identified up to genus level, viz., Cicindela sp. and one up to family level Pentatomidae and six up to order level only, i.e., Coleoptera, Diptera, Lepidoptera, Orthoptera and Thysanoptera (2 specimens). The results suggested that $50 \%$ of the community could be identified to species level with MT-CO1 gene and at least about 8 specimens could possibly be new species for India. The insects thus collected from Kaas plateau were molecularly identified and at least $50 \%$ of collections were delineated to species level on the basis of their DNA barcodes for the first time.
\end{abstract}

Keywords: DNA barcoding, Insects, Kaas plateau, MT-CO1gene, Western-Ghats

\section{INTRODUCTION}

Kaas Plateau is one of the important plateaus in Sahyadri range of Western Ghats located $25 \mathrm{~km}$ west to Satara district of Maharashtra, India (Kaas Plateau, 2016). Total area of plateau is 1792 ha and is an outstanding example representing significant ongoing ecological and biological process in the evolution and developments of terrestrial and fresh water ecosystems and is also a natural habitat for in-situ conservation of biological diversity, therefore, this area included in the World Natural Heritage site by UNESCO. Western Ghats are not true mountains, but are the faulted edge of the Deccan Plateau. They are believed to have been formed during the break-up of the super continent of Gondwana some 160 million years ago (Karanth, 2006). Though, the place inhabits about 850 different species of flowers and other plants such as orchids, Karvy and carnivorous plants (Mohite, 2015), but no efforts have been made to study insect biodiversity in this area. Insects inhabiting this region are the major factors behind the rich biodiversity of this region. Butterflies, bees and wasps help in pollination of the flowering plants, beetles and ants keeps soil healthy by aerating it and improves its retention of rain water, bugs and thrips damages flowering plants. To identify some important insect species of this region, a survey was carried out in Kaas Plateau and different species of insects were collected. Use of DNA sequence data derived from region of MT-CO1 gene has been used widely to estimate phylogenetic relationships across insects followed by Sreejith et al. (2015). In this communication, for the first time an attempt was made to identify those using DNA based, MT-CO1 gene approach.

\section{MATERIALS AND METHODS}

Survey detail and collection of insects: The survey was conducted during post-monsoon period in the 
month of September 2015, in Kaas Plateau of Western Ghats, located in semi-evergreen moist forest in Satara District $\left(17^{\circ} 42^{\prime}\right.$ to $17^{\circ} 45^{\prime} \mathrm{N}$ and $73^{\circ} 47^{\prime}$ to $\left.73^{\circ} 56^{\prime} \mathrm{E}\right)$, Maharashtra. The entire region was bloomed with colourful flowers and there was no sight of bare land in the area. We noticed the activity of insects mostly butterflies, coleopterans and bees attracted towards flowering plants and beetles on the ground. About 150 insects were sampled from 10 spots in $1 \mathrm{~km}$ area, collected with the help of sweep net and aspirator during the trip and were transferred to plastic vials. The specimens were shipped to Division of Molecular Entomology at ICAR-National Bureau of Agricultural Insect Resources (NBAIR), Bengaluru, and adult insects were separated by their distinct morphological characteristics. The insect community collected were represented by 7 insect orders, viz., Lepidoptera, Coleoptera, Hemiptera, Hymenoptera, Diptera, Orthoptera and Thysanoptera. However, in absence of adequate numbers of expert taxonomists, we employed molecular technique based on their DNA for their identification. The specimens that were morphologically designated as tentative species were used for molecular identification based on MT-CO1 gene.

DNA isolation, PCR and sequencing: DNA extraction was performed on single specimen using Qiagen DNeasy® kit, following the manufacturer's protocols. The remaining individual of same species of each insect kept as voucher specimens at $-70^{\circ} \mathrm{C}$ at ICAR NBAIR, Bengaluru. The DNA thus obtained was subjected to PCR amplification of a $658 \mathrm{bp}$ region near the 5 ' terminus of the MT-CO1 gene following standard protocol (Hebert et al., 2003). Primers used for amplification of MT-CO1 gene were: forward primer (LCO 1490 5'-GGTCAACAAATCATAAAGATATTGG-3'), and $\begin{array}{llll}\text { reverse } & \text { primer } & \text { (HCO } & 2198 \\ 5^{\prime}\end{array}$ TAAACTTCAGGGTGACCAAAAAATCA-3'). Polymerase Chain Reaction were carried out in flat capped $200 \mu \mathrm{L}$ volume PCR tubes obtained from M/s Tarsons, Kolkata, India. $50 \mu \mathrm{L}$ reaction volume containing: 5 $\mu \mathrm{L}$ GeNei ${ }^{\mathrm{TM}}$ Taq buffer, $1 \mu \mathrm{L}$ GeNei ${ }^{\mathrm{TM}} 10 \mathrm{mM}$ dNTP mix, $1 \mu \mathrm{L}(20 \mathrm{pmol} / \mu \mathrm{L})$ forward primer, $1 \mu \mathrm{L}(20$ $\mathrm{pmol} / \mu \mathrm{L})$ reverse primer, $1 \mu \mathrm{L} \mathrm{GeNe}^{\mathrm{TM}}$ Taq DNA polymerase $(1 \mathrm{U} / \mu \mathrm{L}), 5 \mu \mathrm{L}$ DNA $(50 \mathrm{ng} / \mu \mathrm{L})$, and 36 $\mu \mathrm{L}$ sterile water. Thermo cycling consisted of an initial denaturation of $94^{\circ} \mathrm{C}$ for $5 \mathrm{~min}$, followed by 30 cycles of denaturation at $94^{\circ} \mathrm{C}$ for $1 \mathrm{~min}$, annealing at $55^{\circ} \mathrm{C}$ for $1 \mathrm{~min}$, extension at $72^{\circ} \mathrm{C}$ for $1 \mathrm{~min}$. PCR was performed using a BioRad C1000 TM Thermal Cycler. The amplified products were analysed on $1.5 \%$ agarose gel electrophoresis (Sambrook et al., 2001) and amplified products were sequenced by M/s Chromous, Bengaluru.

Statistical and phylogenetic analysis: Each specimen PCR sample was bi-directionally sequenced and checked for homology, insertions and deletions, stop codons, and frame shifts by using NCBI-BLAST and ORF finder. All MT-CO1 nucleotide sequences were checked for homology by using BLAST tool of NCBI. Further all the sequences were subjected to phylogenetic analysis and were aligned using Clustal W with default parameters of gap opening penalty 15 , and a gap-extension 6.06 in pairwise and 6.06 in multiple alignments and phylogenetic analysis was performed using MEGA 6.0 software. Neighbour-joining (NJ) tree was constructed (Felsenstein, 1985) by applying 1000 bootstrap support (Saitou et al., 1987) and using a general time reversible (GTR) model with the MTCO1 nucleotide sequences of the insects. The overall transition / transversion bias is $\mathrm{R}$, calculated by following formula $\left[\mathrm{A}^{*} \mathrm{G} * \mathrm{k} 1+\mathrm{T}^{*} \mathrm{C} * \mathrm{k} 2\right] /[(\mathrm{A}+\mathrm{G}) *(\mathrm{~T}+\mathrm{C})]$ by applying Tamura-Nei model in maximum composite likelihood (MCL) method using MEGA 6.0 software. Transition and transversion can be defined as DNA substitution mutations, which was two types. Transtitions are interchanges of two-ring purines $(A-G$ or of one-ring pyrimidines $(\mathrm{C}-\mathrm{T})$, whereas transversons are interchanges of purine for pyrimidine bases, which involve exchange of one ring and two-rings structure.

\section{RESULTS AND DISCUSSION}

Species delineation through MT-CO1 sequences: Based on their morphological characters, the composition of collection was grouped into the following orders, viz., Lepidoptera (3 specimens), Coleopteran (4 specimens), Hemiptera (1 specimen), Hymenoptera (1 specimen), Diptera (2 specimens), Orthoptera (1 specimens) and Thysanoptera (3 specimens) (Table 1). Genomic DNA extracted was confirmed on $1 \%$ agarose gel for insects collected from Kaas Plateau. The identification process employed was MT-CO1 and gene segment of $658 \mathrm{bp}$ was obtained for each species. Maximum similar sequence was taken as tentative identification up to order, family, genera and species levels (Table 1). As no insertions, deletions or stop codons were observed in $2^{\text {nd }}$ frame of DNA sequences from ORF finder, which was chosen for submission to GenBank. The sequence analysis determined occurrence of 15 different insect species, of which 7 could be identified up to species level, viz., Adoretus duvauceli (Blanchard), Apis florea (Fabricius), Blepharella lateralis (Macquart), Coelophora bissellata (Mulsant), Eoophyla excentrica (Speidel), Gynaikothrips uzeli (Zimmerman) and Erionota torus (Evans). In these matches of our sequences with existing GenBank database was $>96 \%$, therefore, were considered as putative species. Among these putative species identified, many have been recorded earlier from different parts of the country, but none from Kaas Plateau. Adoretus duvauceli was recorded by Chandra et al. (2013), A. florea by Khan et al. (2004), B. lateralis by Kumar et al. (1987), C. bissellata by Kapur, (1962), E. excentrica, Gynaikothrips (Denmark et al., 2014) and E. torus (Cock, 2015). One specimen could be identified up to genus level, viz., Cicindela sp., one up to family level - 
Table 1. Insect specimen identification and NCBI-BLAST results of their Cytochrome c oxidase subunit I (MT-CO1) gene sequences for insects collected from Kaas Plateau, Maharashtra, India.

\begin{tabular}{lllcc}
\hline Sl. No. & Sample no. & Submission as & $\begin{array}{c}\text { \% Matching in } \\
\text { BLAST }\end{array}$ & $\begin{array}{c}\text { GenBank accession num- } \\
\text { bers }\end{array}$ \\
\hline 1 & SEQ-1 & Coleoptera** & 85 & KU737490 \\
2 & SEQ-2 & Diptera** & 89 & KU737491 \\
3 & SEQ-3 & Lepidoptera** & 93 & KU737492 \\
4 & SEQ-4 & Adoretus duvauceli & 96 & KU737493 \\
5 & SEQ-5 & Apis florae & 99 & KU737494 \\
6 & SEQ-6 & Cicindela sp*. & 87 & KU737496 \\
7 & SEQ-7 & Blepharella lateralis & 97 & KU737497 \\
8 & SEQ-9 & Orthoptera** & 89 & KU737498 \\
9 & SEQ-10 & Coelophora bissellata & 98 & KU737499 \\
10 & SEQ-11 & Pentatomidae*** & 86 & KU752500 \\
11 & SEQ-13 & Eoophyla excentrica & 98 & KU752542 \\
12 & SEQ-14 & Gynaikothrips uzeli & 99 & KU752543 \\
13 & SEQ-15 & Thysanoptera** & 88 & KU737501 \\
14 & SEQ-16 & Thysanoptera** & 88 & 99 \\
15 & SEQ-17 & Erionota torus & & \\
\hline
\end{tabular}

Specimens with $>96 \%$ matching were submitted as species. Since the sequencing results were matching $<96 \%$ with the existing NCBI website in some insects, we submitted such unidentified specimens up to *Genus, **order and ***family level. (Seven specimens up-to Species level, viz., Sl. No. 4, 5, 7, 9, 11, 12 and 17; one was up to *Genus level, viz., S1. No. 6; one up to ***family level Sl. No. 10; six were up to **Order level, viz., 1, 2, 3, 8, 13 and 14).

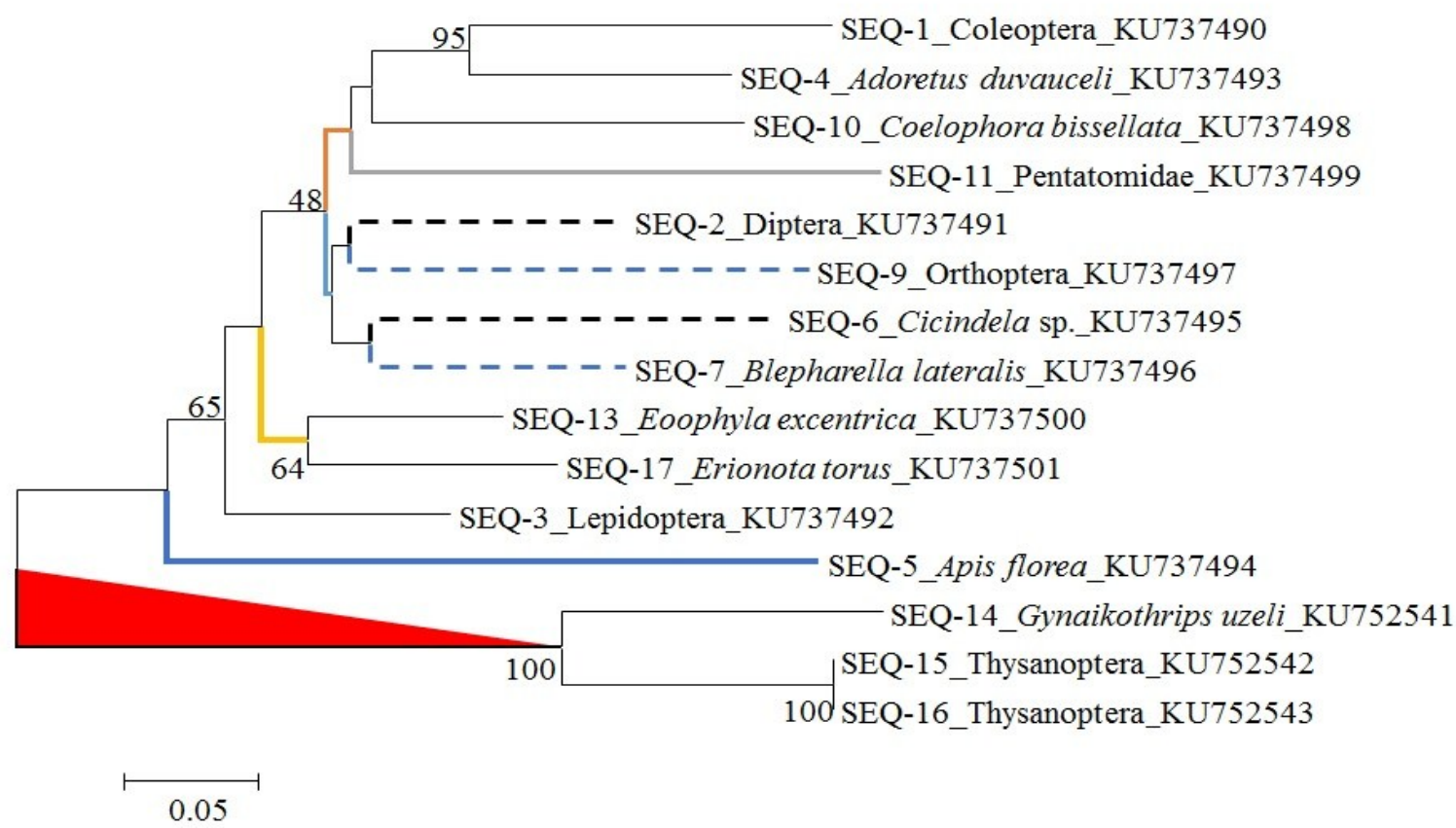

Fig. 1. Phylogenetic tree representing relationship between insects of 7 different orders constructed by MEGA 6.0 by applying $K 2 P / N J$ method.

Pentatomidae and six up to order level only, i.e., Coleoptera (1 specimen), Lepidoptera (1 specimen), Diptera (1 specimen), Orthoptera (1 specimen) and Thysanoptera (2 specimens).

Interpretation of statistical and phylogenetic data: A total of 15 insect mitochondrial DNA sequences were studied according to Kimura's 2 Parameter /
Neighbor-Joining (K2P/NJ) model (Tamura et al., 2013). All these 15 species were clustered into two major clades (Fig. 1). First clade consisted of 5 species belonged to order Coleoptera, Hemiptera, Diptera, Orthoptera, Lepidoptera, and Hymenoptera and another clade consisting of three Thysanopteran species. However, Thysanopteran group separated with the 


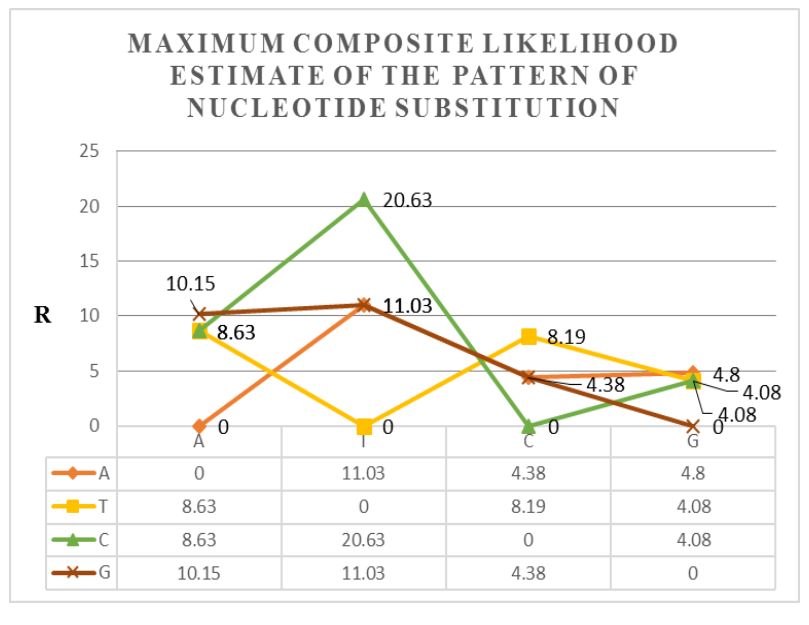

Fig. 2. Pattern of nucleotide substitution among 15 species collected from KAAS Plateau, where $R$ is probability of substitution.

above clade (consisting specimens from six orders) and showed 100 bootstrap (at node) supports within species showing intra species and inter-ordinal relationship. Each entry shows the probability of substitution (r) from one base (row) to another base (Fig. 2). The analysis showed that transitions were more frequent than transversions. Highest transition / transversion value observed for Cytosine/Thymine $(\mathrm{C} / \mathrm{T})$ was 20.63. The overall transition / transversion bias is $\mathrm{R}=$ 0.673 , where $\mathrm{R}$ was calculated by following formula $\left[A * \mathrm{G}^{*} \mathrm{k} 1+\mathrm{T} * \mathrm{C} * \mathrm{k} 2\right] /[(\mathrm{A}+\mathrm{G}) *(\mathrm{~T}+\mathrm{C})]$. The transition / transversion rate ratios are $\mathrm{k} 1=1.176$ (purines) and $\mathrm{k} 2=1.871$ (pyrimidines). The nucleotide frequencies are $30.69 \%$ Adenine, $39.23 \%$ Thymine, $15.58 \%$ Cytosine, and $14.51 \%$ Guanine. There was a total of 603 positions in the final dataset.

The results suggested that $50 \%$ of the community could be identified to species level with MT-CO1 gene and at least about 8 specimens possibly be new species for India. The quantification of biodiversity also revealed that $80 \%$ of specimens were pollinators giving status to this region as "Plateau of Flowers". Insects associated with the Kaas Plateau ecosystem are less studied invertebrates and the present study revealed that there is need for detailed investigation to quantify the diversity of insects in this Plateau.

\section{Conclusion}

The quantification of biodiversity represented insects from six different orders, resulted into determination of possible 15 different species of which $50 \%$ of the species could be identified up to species level through MT - $\mathrm{CO} 1$ gene matched $>96 \%$ with existing GenBank database and remaining $50 \%$ of species could be new species for India. Most of the insect collected were found to be pollinators. Phylogenetic analysis of insects showed interordinal and interspecies relationship among insects. As many groups of insects lack expert taxonomists, the effective management of pest species damaging the crops cannot be undertaken without accurate identification. Therefore, an integrated approach is a current need to identify unknown species of unexplored places in India and the world. Our studies clearly indicated that it is possible to employ MT-CO1 gene for quick, reliable and authentic identification of insect biodiversity, which otherwise requires a detailed morpho-taxonomical studies. An extensive exploration in these areas coupled with large scale sampling of unknown taxa and use of DNA tools will increase the species identification of plateau ecosystems.

\section{ACKNOWLEDGEMENTS}

Authors are thankful to Dr. Ankita Gupta and Dr. Sunil Joshi at ICAR-NBAIR, Bengaluru, Karnataka, for their guidance in separating insects in various orders and to the Director, ICAR-National Bureau of Agricultural Insect Resources, Bengaluru, Karnataka, for providing necessary facilities and encouragement. This work is part of Ph. D. work of the first author, research scholar of Jain University, Jayanagar, Bengaluru, India.

\section{REFERENCES}

Chandra, K. and Gupta, D. (2013). Scarab beetles (Coleoptera: Scarabaeoidea) of Barnawapara Wildlife Sanctuary, Chhattisgarh, India. J. Threat. Taxa., 5 (12): 4660-4671

Cock, M.J.W. (2015). A critical review of the literature on the pest Erionota spp. (Lepidoptera, Hesperiidae): taxonomy, distribution, food plants, early stages, natural enemies and biological control. CAB Reviews, 10: No. 007. doi: 10.1079/PAVSNNR201510007

Denmark, H.A., Fasulo, T.R. and Funderburk, J.E. (2014). Leaf-gall thrips of Ficus -Gynaikothrips ficorum (Marchal) and Gynaikothrips uzeli (Zimmerman) (Insecta: Thysanoptera: Phlaeothripidae). U.S. Department of Agriculture, UF/IFAS Extension Service, University of Florida, IFAS, Florida A \& M University Cooperative Extension Program, and Boards of County Commissioners Cooperating. http://entomology.ifas.ufl. edu/creatures.

Felsenstein, J. (1985). Confidence limits on phylogenies: an approach using the bootstrap. Evol., 39 (4): 783-791

Hebert, P.D.N., Cywinska, A., Ball, S.L. and deWaard, J.R. (2003). Biological identifications through DNA barcodes. Proc. R. Soc. Lond. B. Biol. Sci., 270 (1512): 313 $-321$

Kapur, A.P. (1962). Geographical variations in the colour pattterns of some Indian ladybeetles (Coccinellidae: Coleoptera). Part I. Coccinella septempunctata Linn., C. transversalis Fabr. and Coelophora bissellata Muls. Proceedings of the First All India Congress of Zoology, 2: 479-492

Karanth, K.P. (2006). Out-of-India Gondwanan origin of some Asian biota. Curr. Sci., 90 (6): 789-792

Kass Plateau (2016). 'Wikipedia: Kaas Plateau' pp.1. Retrieved March, 292016 from https://en.wikipedia.org/ wiki/Kaas_plateau

Khan, M.S., Beena Kumari., Rohilla, H.R., Kaushik, H.D. 
Rakshit Ojha et al. / J. Appl. \& Nat. Sci. 8 (4): 2170-2174 (2016)

and Arora, R.K. (2004). Analysis of insecticide residues in honeys from apiary (Apis mellifera) and wild honey bee (Apis dorsata and Apis florea) colonies in India. $J$. Apic. Res., 43 (3): 79-82

Kumar, N. and Yadav, R.P. (1987). Records of Blepharella lateralis MacQuart and Carcelia sp - two indigenous parasitoids of Spilosoma, Diacrisia obliqua Walker from Bihar India. Curr. Sci., 56 (22): 1192-1193

Mohite, A.S. (2015). Flowers of KAAS PLATEAU, $2^{\text {nd }}$ ed., National offset printers, Satara, Maharashtra, India. pp. 6-7

Saitou, N. and Nei, M. (1987). The Neighbor-joining method: a new method for reconstructing phylogenetic trees.
Mol. Biol. Evol., 4 (4): 406-425

Sambrook, J.F. and Russell, D.W. (2001). Molecular cloning: A laboratory manual, $3^{\text {rd }}$ Edition, Cold Spring Harbor Laboratory Press, Long Island, New York, USA. pp. 2100

Sreejith, K. and Sebastian, C.D. (2015). Molecular phylogeny and genetic analysis of green leafhopper Nephotettix virescens (Distant) using mitochondrial COI gene. Indian J. Sci. Technol., 8 (1): 61-64

Tamura, K., Stecher, G., Peterson, D., Filipski, A. and Kumar, S. (2013). MEGA6: Molecular Evolutionary Genetics Analysis version 6.0. Mol. Biol. Evol., 30 (12): 2725-2729 